\title{
RF Characteristics of the APS Storage Ring Isolation Valve*
}

\author{
J. J. Song, R. L. Kustom \\ Advanced Photon Source \\ Argonne National Laboratory \\ 9700 S. Cass Ave, Argonne, IL 60439, USA
}

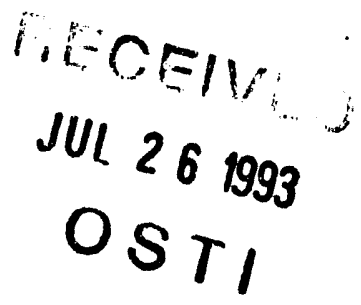

\section{Abstract}

The RF impedance of the isolation valve of the APS storage ring system was measured by the wire method with a synthetic pulse technique. The coupling impedance as well as the energy loss of the sector valve with and without an RF liner or screen, and the flange gap of the various sizes was measured. There appear to be resonances at certain frequencies without an $\mathrm{RF}$ liner that might cause an unacceptably large coupling impedance. Data with various sizes of the flange gap show that good RF contact around any flange is necessary. The impedance due to intrusions into the beam chamber was also measured. The results are compared with the computer simulation from MAFIA.

\section{INTRODUCTION}

The beam coupling impedance must be kept small so that the desired operating current (a maximum of $300 \mathrm{~mA}$ with a life-time of at least $10 \mathrm{hrs}$ ) can be achieved. To reduce the coupling impedance of the vacuum components in the APS storage ring, there are many places such as bellows, liners, RF isolation valves, $R F$ ion pumps, and screened photon absorbers, that have various $R F$ shielding structures. Among the concerns with RF shielding structures are vacuum, synchrotron radiation, RF heating, and coupling impedance. The photon absorber requires an intrusion into the beam chamber in front of the isolation valve to protect against direct photon radiation.

This paper presents the results of measurements using the wire method with a synthetic pulse technique [1]. A gating technique was applied to obtain the frequency domain reflection. The coaxial wire method is a widespread tool for bench measurements of beam coupling impedance. By sending a short pulse through the center wire of a transmission line or a vacuum chamber, the current distribution on the inner surface of the beam chamber can be obtained which corresponds similarly to the current distribution produced by a passing beam bunch.

The measurement procedure employed here is known as a synthetic pulse technique. Since any pulse defined as a function of amplitude over time can also be defined by its frequency spectrum of amplitude and phase, the synthetic pulse can be generated in the time domain (TD) via inverse fast Fourier transform (IFFT) from measurements taken in the frequency domain (FD). This leads to higher spectral density than realtime pulse measurements. thus giving a higher dynamic range and better repeatar ity.

* Work supported by US. Department of Energy, Office of Basic Sciences, under contract W-31-109-END-38.

\section{LOSS PARAMETER AND IMPEDANCE}

For a given particle beam bunch with charge $q$, the energy loss of the bunch is

$$
\Delta \mathrm{E}=\mathbf{k q}^{2}=2 \mathrm{Z}_{\mathrm{Lq}} \mathrm{q}^{2} \frac{\int \mathrm{I}_{1}\left(\mathrm{I}_{1}-\mathrm{I}_{2}\right) \mathrm{dt}}{\left(\int \mathrm{I}_{2} \mathrm{dt}\right)^{2}}(\mathrm{eV}),
$$

where $\mathrm{Z}_{\mathrm{L}}$ is the characteristic impedance of the transmission line or the wire running through the beam pipe, $I_{1}$ is the current flowing through the reference chamber (REF), $I_{2}$ is the current flowing through the device under test (DUT), and $k$ is the loss parameter that is physically the energy loss in $\mathrm{eV}$ for a bunch with a unit charge passing through the vacuum component. Thus the longitudinal loss parameter, $k$, can be computed from measurements by the integration of the current over the pulse length such as:

$$
k=2 Z_{L} \frac{\int I_{1}\left(I_{1}-I_{2}\right) d t}{\left(\int I_{2} d t\right)^{2}} \quad(V / p c)
$$

It must be pointed out that $\mathbf{k}$ is also a function of particle bunch length, $\sigma$. The broadband impedance represents the impedance of a non-resonant device (e.g. any little discontinuity around the storage ring), which is given as:

$$
Z=\frac{Z(\omega)}{n}
$$

assuming that $Q=1$, where $n=\omega / 2 \pi f_{0}\left(f_{O}=1 / T_{0}\right.$ is the revolution frequency of the beam in the storage ring) and $Z(\omega)$ is the individual mode impedance of the DUT in the FD. $Z(\omega)$ can also be computed from the measurements,

$$
Z(\omega)=2 Z_{L} \frac{\left[I_{1}(\omega)-I_{2}(\omega)\right]}{I_{2}(\omega)}
$$

where $I_{1}(\omega)$ and $I_{2}(\omega)$ are the current measured in the FD with the REF and the DUT, respectively. The wake potential is defined as the integrated perturbed electromagnetic energy acting on the beam bunch with a unit charge and can be also derived by transforming Eq. (4) into the TD,

$$
W_{b}(t)=-\frac{2 Z_{L}\left[I_{1}(t)-I_{2}(t)\right]}{q} \quad(V / p c) .
$$




\section{EXPERIMENTAL SETUP}

\section{A. RF Liner}

A VAT isolation valve (model S-47) was tested to evaluate the RF characteristics of the RF liner. An RF liner of the model S -47 consists of 64 shielding screens each $1.8 \mathrm{~mm}$ wide, $4.3 \mathrm{~cm}$ long, $0.1 \mathrm{~mm}$ thick with $1.3 \mathrm{~mm}$ gap. More detailed specifications can be found in reference [2].

As depicted in Fig. 1, a network analyzer (HP 8510B) was used to measure the two-port S-parameters of the DUT. All the data was transferred to the PC 486 computer for analysis, using the HP Basic 6.0 program language.

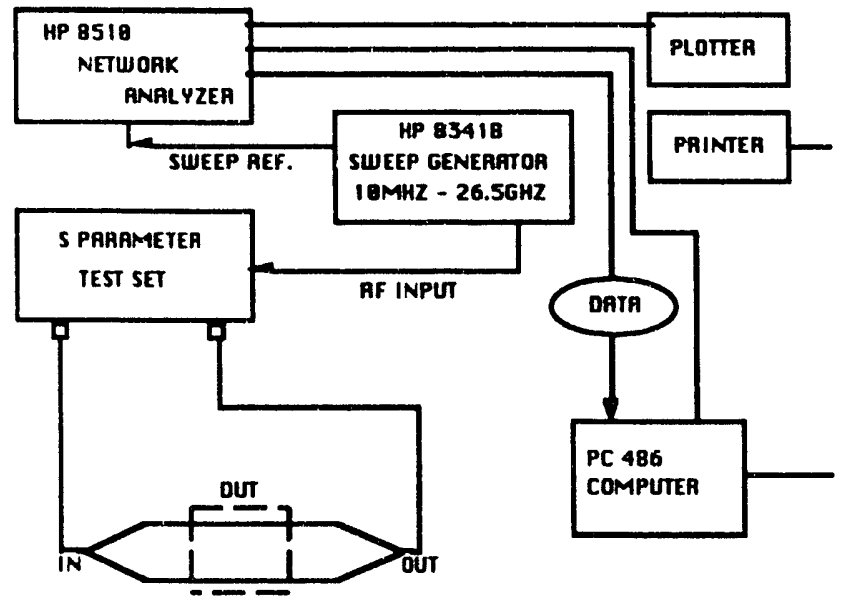

Fig.1 Experimental Setup for Synthetic Pulse Technique

\section{B. Photon Absorber Intrusion}

The measurement was done with two different types of intrusions: a round one ( $7 \mathrm{~cm}$ in diameter) and a linear one (10 $\mathrm{cm}$ in length). They were inserted from the antechamber through the $1-\mathrm{cm}$ slot into the beam chamber. The intrusion was varied from 0 to $2.5 \mathrm{~cm}$ in $0.5 \mathrm{~cm}$ steps. The data was taken with the synthetic pulse techniques as mentioned above. To verify the synthetic pulse techniques, the measurement was also done with the real-time pulse.

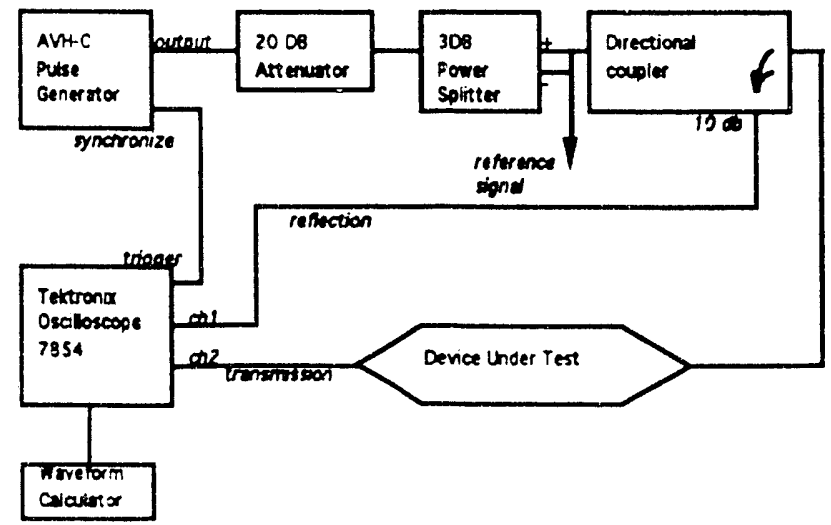

Fig.2 Experimental Setup for Real-Time Pulse Technique.
Figure 2 shows the setup for real-time pulse measurement. The signal is an 8-Volt 140-ps Gaussian pulse generated by an AVH-C pulser. The 20-dB attenuator is used to prevent the pulsar from load mismatch. A Tektronix 7854 sampling oscilloscope that can record data with up to 512 points on one screen was used with its waveform averaging function to significantly reduce the random error. Waveform parameters (area, RMS value, maximum, minimum, etc.) are ralculated using the attached calculator.

\section{MEASUREMENTS AND RESULTS}

\section{A. RF Liner}

The typical transmission data (S21) in the frequency domain is shown in Fig. 3. The top curve comes from the reference beam chamber and the bottom curve is from the standard valve without an $R F$ liner. As seen, there are resonances at 2.3, 5.9 , and $9.4 \mathrm{GHz}$. The Qs of these resonances are high enough to unacceptably lower the thresholds for multibunch beam instabilities. The RF liner in the valve solves the problem as shown in Fig. 4. The cavity-like resonances are eliminated but the broadband impedance of the DUT is still significant (maximum of $\mathrm{Z} / \mathrm{n} \sim 0.002 \Omega$ ).

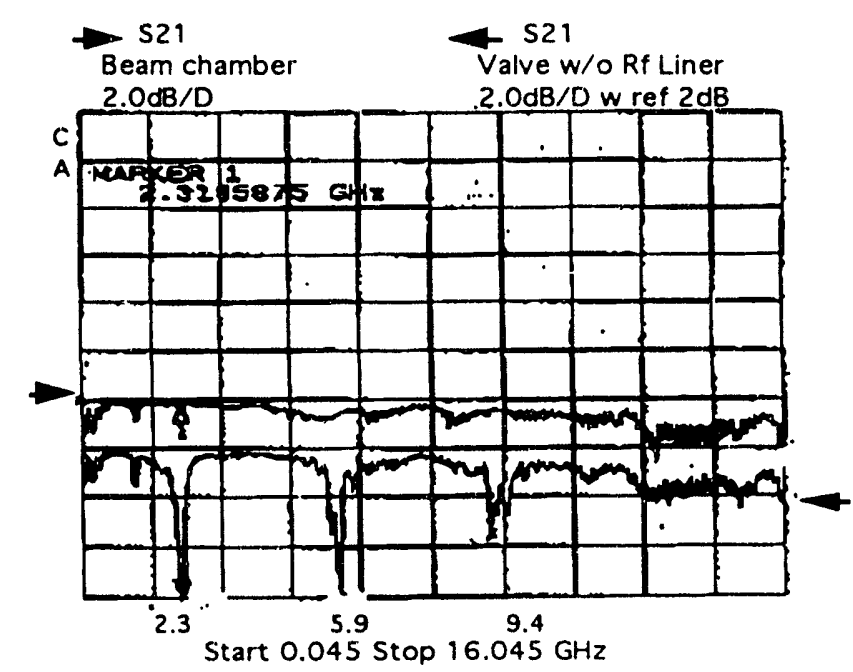

Fig. 3 The transmission in FD

A gap existed at the flanges between the isolation valve and the short reference beam chamber. This generated a weak peak around $2 \mathrm{GHz}$. By filling the gap with an $\mathrm{RF}$ gasket for the flange on each side, the impedance due to the whole system was reduced to about $4 \times 10^{-4} \Omega$ (see Fig. 6). Also using the gating function built into the HP 8510 , the impedance contribution due to the valve itself is separated from the gasket. More detailed measurement results can be found in reference [3].

The loss factor was measured in the time domain and the results are summarized in Table 1 . The bunch length-dependence of the loss factor is plotted in Fig. 4. This was done by varying the frequency span to get a different synthetic pulse length. 
Table 1 Impedance and Loss Factor of Isolation Valve

\begin{tabular}{|l|l|l|}
\hline Isolation Valve & $\begin{array}{l}\text { Impedanc } \\
\mathrm{e}\end{array}$ & $\begin{array}{l}\text { Loss } \\
\text { Factor }\end{array}$ \\
\hline & $\mathrm{Z} / \mathrm{n}(\Omega)$ & $\mathrm{K}(\mathrm{V} / \mathrm{pc})$ \\
\hline w/o RF Liner, Gasket & 0.08 & 0.1 \\
\hline $\begin{array}{l}\text { w RF Liner, but w/o } \\
\text { Gasket }\end{array}$ & 0.002 & 0.01 \\
\hline $\begin{array}{l}\text { w RF Liner, Gasket, but } \\
\text { no Gating }\end{array}$ & $4 \times 10^{-4}$ & $4 \times 10^{-3}$ \\
\hline $\begin{array}{l}\text { w RF Liner, Gasket, \& } \\
\text { Gating }\end{array}$ & $4 \times 10^{-5}$ & $\begin{array}{l}\text { not avail- } \\
\text { able }\end{array}$ \\
\hline
\end{tabular}

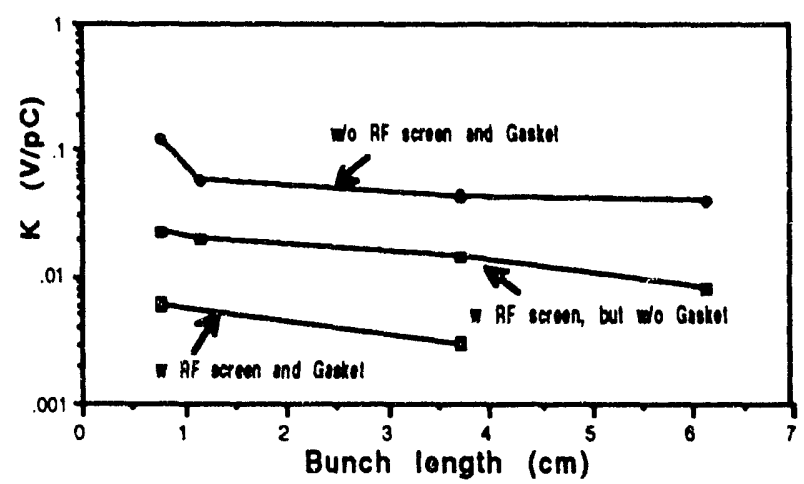

Fig. 4 Loss Factor of Isolation Valve, varying the frequency span to get a different bunch length of the beam

\section{B. Photon Absorber Intrusion}

The energy loss due to the intrusion can also be measured with the reflected signal similar to $\mathrm{Eq}$. (1). The loss parameter calculated with the synthetic pulse from S11 is shown in Fig. 5. It can be easily seen that the loss parameter of the linear intrusion is significantly less than the round one with same amount of intrusion. A similar conclusion has been made with MAFIA calculations. [4]

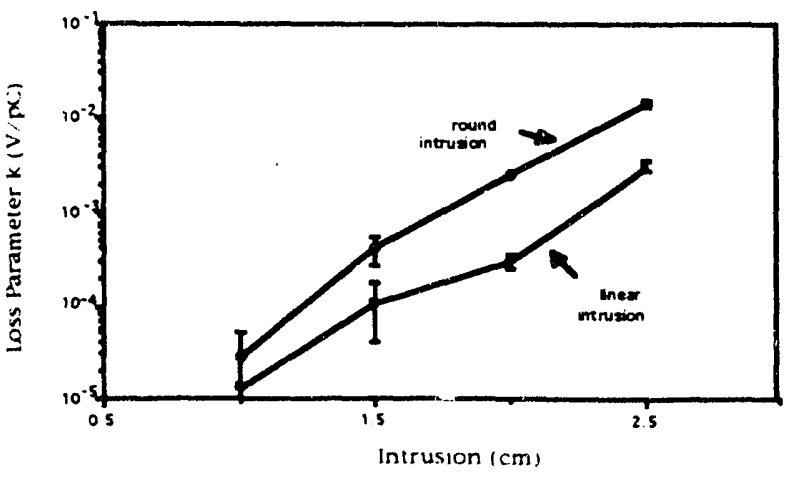

Fig. 5 Loss Parameter for Round and Linear Intrusions Obtained from Synthetic Pulse Measurements

\section{Synthetic Pulse vs. Real-Time Pulse}

To verify the synthetic pulse techniques, a real-time pulse was employed to measure the loss parameter. The transmission data was measured with the round intrusion, having similar measurement parameters such as pulse length, average number, etc. [5]. As one can see in Fig. 6, the results from the two techniques are in very good agreements. But the measurement error with the real-time pulse is larger because of jitter in the pulse generator. The real-time pulse is not suitable for small loss factor measurement below $1 \times 10^{-3} \mathrm{~V} / \mathrm{pc}$.

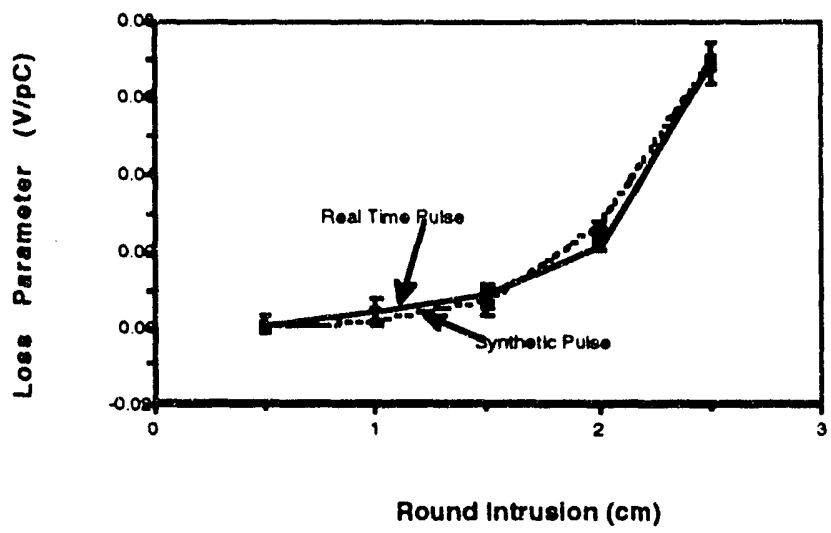

Fig. 6 Synthetic Pulse vs. Real-Time Pulse, S21 measured with the Round Intrusion.

\section{CONCLUSION AND DISCUSSION}

An RF liner in the isolation valve and a good RF contact between the flanges reduced the coupling impedance to a satisfactorily low level. The measured impedance due to 160 isolation valves was about 0.4 percentage of the total APS impedance budget.

The intrusion due to the photon absorber should not penetrate more than $1.5 \mathrm{~cm}$ from the slot into the bean chamber to avoid increasing the coupling impedance. The linear intrusion gives less impedance than the round intrusion.

\section{ACKNOWLEDGMENTS}

The author would like to thank J. W. Howell for his mechanical engineering support. Also thanks must be given to $D$. $F$. Voss and P. Young for their technical support.

\section{REFERENCES}

[1] J. J. Song, "Experimental Study of Coupling Impedance," APS Light Source Note LS-201. ANL, Oct 11, 1991.

[2] VALVE DATA SHEET No. e-72453-01 for RF All-Metal Gate Valve from VAT.

[3] J. J. Song, "RF Characteristics of the APS Storage Ring Isolation Valve," to be published.

[4] L. Teng, "Single and Multibunch Instability," presented at the Accelerator Advisory Committee Meeting, Nov. 11-12 1991.

[5] J. H. Zhou, "Intrusion Measurements, Synthetic Pulse vs. Real Pulse," to be published. 


\section{DISCLAIMER}

This report was prepared as an account of work sponsored by an agency of the United States Government. Neither the United States Government nor any agency thereof, nor any of their employees, makes any warranty, express or implied, or assumes any legal liability or responsibility for the accuracy, completeness, or usefulness of any information, apparatus, product, or process disclosed, or represents that its use would not infringe privately owned rights. Reference herein to any specific commercial product, process, or service by trade name, trademark, manufacturer, or otherwise does not necessarily constitute or imply its endorsement, recommendation, or favoring by the United States Government or any agency thereof. The views and opinions of authors expressed herein do not necessarily state or reflect those of the United States Government or any agency thereof. 

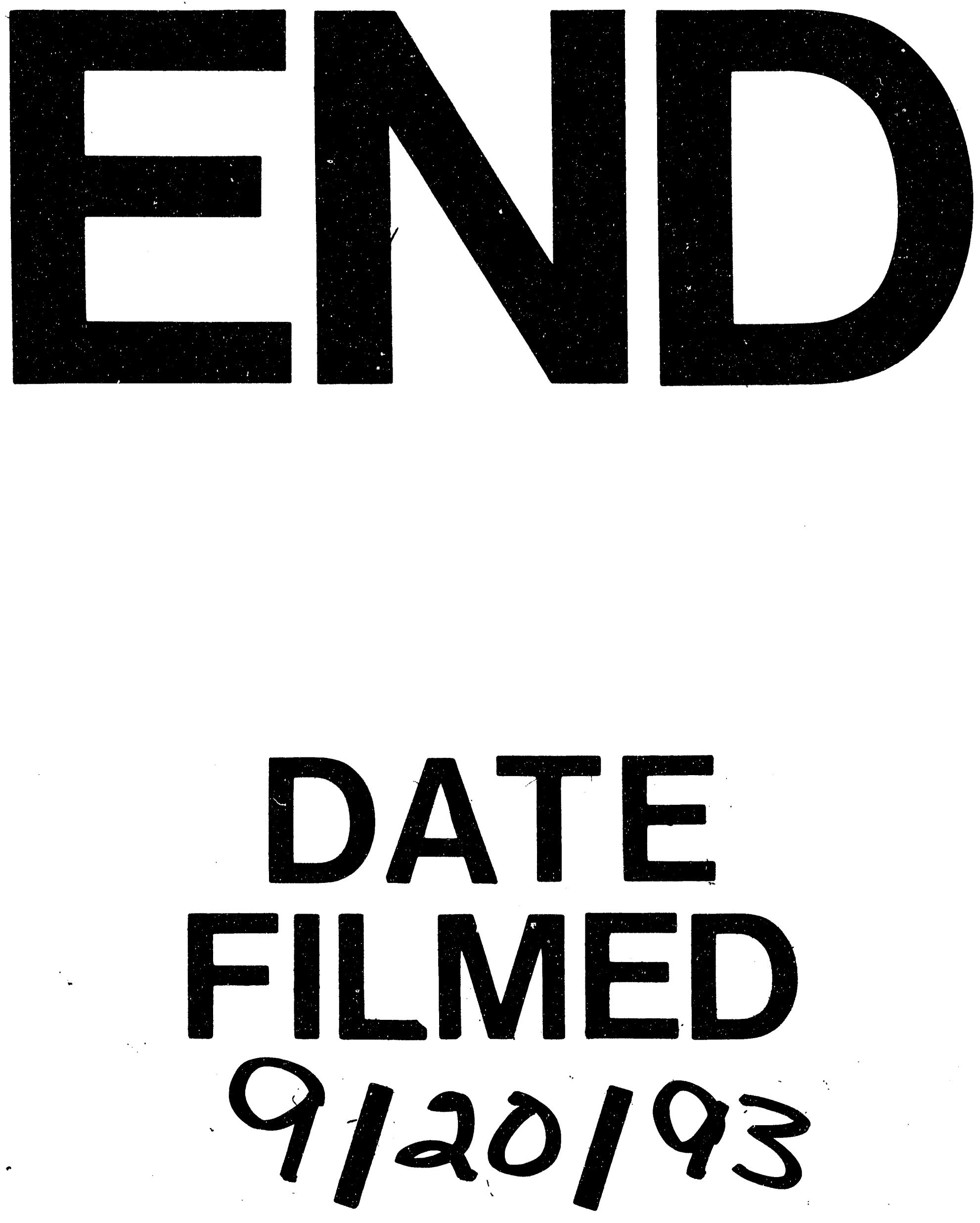
